\title{
Bilateral endogenous Escherichia coli endophthalmitis: a devastating complication in an insulin-dependent diabetic
}

\author{
RS Walmsley, DB David, RN Allan, GR Kirkby
}

\begin{abstract}
Summary
We report a case of bilateral endogenous Escherichia coli endophthalmitis in an insulin-dependent diabetic. This condition appears to occur almost exclusively in diabetics, and is invariably related to a urinary tract infection. Treatment of any infection in diabetics should be aggressive, and any deterioration in vision should be addressed promptly.
\end{abstract}

Keywords: endophthalmitis, Escherichia coli, diabetes mellitis

Endogenous, or secondary, endophthalmitis is a rare but devastating complication of septicaemia. The following case report highlights the need for physicians involved in the care of diabetic patients to assess visual symptoms promptly and ensure adequate treatment of primary infections.

\section{Case report}

A 62-year-old insulin-dependent diabetic man was admitted with a two-day history of rigors and dysuria. He had a significant past medical history of diabetes mellitus since 1983 requiring insulin from 1986, diabetic retinopathy requiring laser therapy in 1986, and hypertension since 1992. Although he was an infrequent attender at the diabetic clinic his glycaemic control was reasonable, with fructosamine levels around the upper limit of normal. On admission he was not on any antihypertensive medication and self-administering once daily human isophane insulin. On examination he was toxic and febrile with an oral temperature of $39^{\circ} \mathrm{C}$. Blood tests revealed an elevated white cell count of $18 \times 10^{9} \mathrm{~g} / \mathrm{l}$, glucose $16 \mathrm{mmol} / \mathrm{l}$, and deteriorated renal function with urea $40.6 \mathrm{mmol} / 1$ and creatinine $651 \mu \mathrm{mol} / 1$. A diagnosis of urinary tract infection was made and treatment started with intravenous ampicillin ( $1 \mathrm{~g}$ eight hourly). By the second day he was clinically improved and apyrexial, blood cultures taken on the day of admission grew Escherichia coli resistant to ampicillin. He was therefore changed to oral cephalexin. On the fifth day he complained of difficulty reading. On the ninth day he was seen by the ophthalmologists. The right eye was noted to be intensely infected, with an hypopyon and no fundal view could be obtained (figure). Visual acuity was reduced to perception of light only. In the left eye the visual acuity was reduced to $6 / 60$ and was also markedly infected, with the vitreous being heavily infiltrated with cells. The inferior retina was largely obscured by pre-retinal pus. His acuity assessed two months previously had been $6 / 9$ in each eye, when fundoscopy with dilated pupils by a diabetologist was normal.

A right vitreous biopsy was taken, followed by bilateral intravitreal and subconjunctival injections of cefuroxime $(2.5 \mathrm{mg}$ and $100 \mathrm{mg}$, respectively). Microscopy showed Gram negative bacilli and subsequent culture confirmed $E$ coli with the same antibiotic sensitivities to that grown in earlier urine and blood cultures. Topical steroids and mydriatics, with subconjunctival betamethasone $(4 \mathrm{mg}$ ) to the right eye, were supplemented by oral prednisolone $(30 \mathrm{mg}$ od) on the fifth day and intravenous ciprofloxacin substituted for the cephalosporin in an attempt to achieve higher intravitreal antibiotic levels. Oral ciprofloxacin was continued for 10 weeks, with systemic steroids being phased out over this time. The right eye did not recover and became phthisical, but the left eye gradually recovered from the infection. Four months later severe proliferative diabetic retinopathy with vitreous haemorrhage developed requiring formal pars plana vitrectomy and laser therapy. Eight months after his diagnosis of endophthalmitis he has no perception of light in the right eye and an

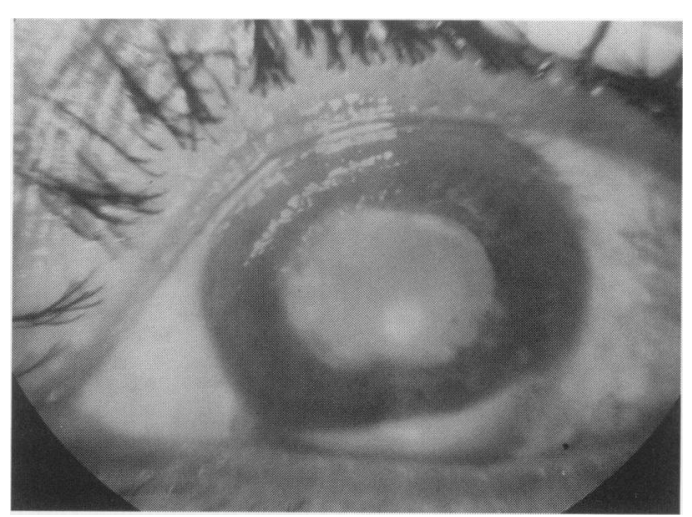

Figure Photograph of right eye showing hypopyon, posterior synechia and loss of red reflex 
Table Case reports of bilateral endogenous endophthalmitis due to Escherichia coli in diabetic patients

\begin{tabular}{|c|c|c|c|c|c|}
\hline $\begin{array}{l}\text { Author } \\
\text { (ref) }\end{array}$ & $\begin{array}{l}\text { Age } \\
\text { (years) }\end{array}$ & Sex & Primary sepsis & Treatment & Outcome \\
\hline Fanning $^{7}$ & 56 & $\mathbf{M}$ & $\begin{array}{l}\text { UTI } \\
\text { ^gangrenous toe, } \\
\text { osteomyelitis }\end{array}$ & iv chloramphenicol+gentamicin & bilateral evisceration \\
\hline Cohen $^{8}$ & 62 & $\mathbf{M}$ & UTI & $\begin{array}{l}\text { oral antibiotics }+ \text { prednisolone } \\
\text { iv cephalosporin +chloramphenicol } \\
\text { subconjunctival gentamicin }\end{array}$ & $\begin{array}{l}\text { L: enucleation } \\
\text { R: no perception of light }\end{array}$ \\
\hline Zakka $^{1}$ & 68 & $\mathbf{F}$ & $\begin{array}{l}\text { UTI } \\
\text { *splenic abscess, } \\
\text { endocarditis }\end{array}$ & iv ampicillin & $\begin{array}{l}\text { L: hand movement at } 12 \text { inches } \\
\mathbf{R} \text { : perception of light }\end{array}$ \\
\hline present case & 62 & $\mathbf{M}$ & UTI & $\begin{array}{l}\text { iv antibiotics } \\
\text { subconjunctival cefuroxime+betamethasone } \\
\text { intravitreal cefuroxime } \\
\text { oral antibiotics }+ \text { prednisolone }\end{array}$ & $\begin{array}{l}\text { L: } 6 / 36 \\
\text { R: no perception of light }\end{array}$ \\
\hline
\end{tabular}

UTI=urinary tract infection; iv=intravenous. * secondary sites of infection

\begin{tabular}{|l|}
\hline Endophthalmitis: causes \\
\hline Exogenous: secondary to trauma (including \\
surgery) \\
Endogenous (metastatic) arising from: \\
- distal focus of infection (eg, pyelonephritis, \\
endocarditis, pneumonia, meningitis) \\
- injection of infected material (eg, intravenous \\
drug abusers) \\
- indwelling cannulae (eg, lines used for \\
intravenous alimentation) \\
\hline
\end{tabular}

acuity of $6 / 36$ in the left. Intravenous pyelogram and cystoscopy, performed because of persistent microhaematuria, were normal and his creatinine fell to $251 \mu \mathrm{mol} / \mathrm{l}$, although this has risen latterly and renal biopsy has confirmed classical diabetic nephropathy.

\section{Discussion}

Endogenous endophthalmitis is a rare but devastating complication of septicaemia. $\mathrm{Re}-$ ports in the medical literature have associated it with pyelonephritis, ${ }^{1}$ endocarditis, ${ }^{2}$ meningitis $^{3}$ and pnuemonia, ${ }^{4}$ with the immunocompromised especially at risk. ${ }^{5} \mathrm{~A}$ recent review of the 10 cases of endogenous $E$ coli endophthalmitis reported shows that nine were diabetics. Eight of them had urinary tract infections as the primary source of sepsis and of 13 infected eyes, 10 had to be removed. ${ }^{6}$ There have been, to our knowledge, only three cases of bilateral $E$ coli endophthalmitis previously, ${ }^{1,7,8}$ the details of which are summarised in the table.

Urinary tract infections are more common in diabetics than in the nondiabetic population. In community-acquired infections, Gram negative organisms predominate and $E$ coli still make up over $50 \%$ of isolates, with a suggested increase in Klebsiella species in the diabetic population. ${ }^{9}$ Resistance to ampicillin of between 30 and $50 \%$ is well recognised in $E$ coli both internationally and in this health authority. It is interesting to note that one of the other cases of bilateral endophthalmitis was treated with oral antibiotics for his urinary tract infection for 14 days despite continued fever

\section{Endophthalmitis: diagnostic features}

- decreased visual acuity, with or without ocular or orbital pain

- redness of the eye, sometimes with conjunctival or periorbital oedema

- posterior synechia

- hypopyon

- loss of red reflex/development of white reflex due to vitreal infiltration with inflammatory debris

\section{Endophthalmitis: management} guidelines

- urgent referral to ophthalmologist

- attempt to isolate organism by vitreous biopsy

- intra-orbital and intravenous antibiotics

- topical and possibly systemic corticosteroids

\section{Learning points}

- endogenous Escherichia coli endophthalmitis is rare and occurs almost exclusively in diabetics

- treatment of any infections in diabetics should be aggressive and care should be taken to cover the likely pathogens

- any deterioration in vision should be assessed promptly

- unconscious patients should have regular ophthalmoscopy

- the outcome of endogenous endophthalmitis is almost always poor, but aggressive intervention can be sight saving

and bacteriuria, the endophthalmitis being diagnosed on the 17th day. It could be argued that the case reported here was treated intially with an inappropriate antibiotic regime, and together with poor prognostic factors of delay in diagnosis and infection with a Gram negative organism, a bad outcome might have been predicted. ${ }^{10}$ However, compared to the other cases reported the outcome was marginally better. This is likely to be due to the 
aggressive treatment with intravitreal and systemic antibiotics combined with steroid therapy.

Endogenous $E$ coli endophthalmitis appears to occur almost exclusively in diabetics, and is invariably related to a urinary tract infection. Treatment of any infection in diabetics should be aggressive and care should be taken to cover the likely pathogens. The outcome of $E$ coli

1 Zakka K, Hirose T. Bilateral endogenous Escherichia coli endophthalmitis. Ann Ophthalmol 1985; 17: 212-5.

2 Hornblass A, To K, Code DJ, et al. Endogenous en dophthalmitis in subacute bacterial endocarditis. $A m \mathcal{f}$ Ophthalmol 1989; 108: 338-9.

3 Williams DN, Geddes AM. Meningococcal meningitis complicated by pericarditis, panophthalmitis and arthritis $B M \mathcal{f}$ 1970; 2: 93 .

4 Johnson AG. Metastatic septic endophthalmitis. South Med f 1969; 62: 879-80.

5 Deutsch D, Adler S, Teller J, et al. Endogenous candidal endophthalmitis. Ann Ophthalmol 1989; 21: 260-8.

6 Park SB, Searl S, Aquavella JV, Erdey RA. Endogenous endophthalmitis caused by Escherichia coli. Ann Ophthalmol 1993; 25: $95-9$. endogenous endophthalmitis is invariably poor and so any deterioration in vision should be assessed promptly as it is not necessarily painful. The alteration of the red reflex to a whitish reflex is an important early sign. In settings where patients cannot communicate, periodic examination of the fundi should be undertaken. Thankfully this condition remains rare.

7 Fanning WL, Stubbert J, Irwin ES, Aronson MD. A case of bilateral Escherichia coli endogenous endophthalmitis. Am $\mathcal{F}$ Med 1976; 61: 295-

8 Cohen P, Kirshner J, Whiting G. Bilateral endogenous Escherichia coli endophthalmitis. Arch Intern Med 1980; 140 1088-9.

9 Lye WC, Chan RKT, Lee EJC, Kumarasinghe G. Urinary tract infections in patients with diabetes mellitus. $\mathcal{F}$ Infect 1992; 24: $169-74$.

10 Puliafito CA, Baker AS, Haaf J, Foster CS. Infectious endophthalmitis: review of 36 cases. Ophthalmology 1982; 89: $1055-66$.

\title{
Elevated serum prostate-specific antigen and pancreatic carcinoma
}

\author{
LR Ranganath, GA Lewis, BT Nobbs, PF Goddard, DC Rangedera
}

\section{Summary \\ We report a case of elevated serum prostate-specific antigen-like immuno- reactivity in a man with a disseminated pancreatic carcinoma}

Keywords: prostate-specific antigen, prostatic biopsy, pancreas

Measurement of serum prostate-specific antigen (PSA) is said to be a specific and sensitive tool in the diagnosis of prostatic cancer. ${ }^{1}$ It has been said that PSA is not present in any other normal tissue obtained in men apart from the prostate, nor is it produced by cancers of the breast, lung, colon, rectum, stomach, thyroid or pancreas. ${ }^{2}$

Epsom General

Hospital, Epsom,

Surrey, KT18 7EG,

UK

Department of

Chemical Pathology

LR Ranganath

GA Lewis

BT Nobbs

PF Goddard

Department of

Medicine for the

Elderly

DC Rangedera
A 79-year old man was admitted with a fourmonth history of weight loss, diarrhoea and abdominal pain. Physical examination and investigations including ultrasound, computed tomography (CT) of abdomen and fine needle biopsy of a retroperitoneal mass suggested the diagnosis of adenocarcinoma of the pancreas with multiple secondary metastases in the liver. Bone scans and chest X-ray excluded any skeletal or thoracic spread. Routine haematology and biochemistry investigations were nor- mal except for serum $\gamma$-glutamyl transpeptidase, amylase and erythrocyte sedimentation rate which were noted to be $85 \mathrm{U} / 1$ (ref range $1-28$ ), $150 \mathrm{IU} / 1$ (ref range 30-110) and $33 \mathrm{~mm} / \mathrm{h}$, respectively. Serum PSA and acid phosphatase measurements were requested at the time of admission and showed an unexpectedly high value for PSA. Prostate-specific acid phosphatase levels of 1.6 and $2.2 \mathrm{IU} / 1$ (tartrate labile fraction) (ref range $0.1-2.8$ )

\begin{tabular}{|l|}
\hline Causes of raised serum PSA \\
\hline Analytical interference \\
Prostatic \\
- prostatitis \\
- prostate infarcts \\
- benign enlargement \\
- carcinoma \\
Non-prostatic \\
- breast milk \\
- salivocrine sweat glands ${ }^{\star}$ \\
- para-urethral gland \\
- renal cell adenocarcinoma \\
- breast tumours \\
- apocrine sweat gland tumours \\
${ }^{\star}$ not detected to be high in blood \\
$\star_{\star}^{\star}$ only with assays using polyclonal antisera \\
\hline
\end{tabular}

